\title{
О ПОВЫШЕНИИ ЭФФЕКТИВНОСТИ ЗАКОНОТВОРЧЕСКОГО ПРОЦЕССА В УСЛОВИЯХ ДЕМОКРАТИЧЕСКИХ ПРЕОБРАЗОВАНИЙ
}

\begin{abstract}
Аннотация: В статье дается анализ факторов, способствующих повышению эффективности законотворческого проиесса в Российской Федерации. С позиции современного юридического научного знания исследованы особенности современного законотворчества с учетом происходящих в настоящее время демократических преобразований. Автор анализирует увеличение динамики законодательной деятельности на федеральном и региональном уровнях, делает вывод о необходимости развития механизма последовательного совершенствования законодательства в виде института народной правотворческой инициативы как института непосредственной демократии. Анализируется важность фактора своевременности принятия закона, участия в законотворческом проиессе научной юридической среды. Методологической основой статьи является совокупность приемов и методов исследования-структурно-функиионального, сравнительно-правового, статистического, формально-юридического, конкретно-исторического. Также использованы абстрагирование, анализ, синтез. Научная новизна статьи состоит в рассмотрении тех аспектов повышения эффективности законотворческой деятельности, которые в юридической науке проанализированы недостаточно. С позиции современного научного подхода проведено исследование факторов повышения эффективности законотворческого проиесса применительно к современным условиям демократических преобразований. Сделаны выводы о необходимости усиления авторитета закона, координации законотворчества на федеральном и региональном уровне.

Ключевые слова: Законотворчество, демократия, эффективность, закон, законодательство, реформы, законопроекты, законотворческий прочесс, правовое государство, законотворческая практика.

Abstract: This article analyzes the factors that promote the increase of effectiveness of the lawmaking process in the Russian Federation. From the perspective of modern juridical scientific knowledge the author researches the peculiarities of modern lawmaking with consideration of the current democratic reforms. The author analyzed the increase in the dynamics of the legislative work on the federal and regional levels, and makes a conclusion on the need for development of a mechanism for sequential improvements to the legislation in form of an institution of public lawmaking initiative as an institution of direct democracy. Analysis is given to the importance of the factor of the timeliness of passing a law, and participation of the scientific juridical community in the legislative process. From the position of modern scientific approach a research is conducted on the factors of improving the efficiency of legislative process pertaining to the modern conditions of democratic reforms. Conclusions are made on the necessity to strengthen the authority of the law, and coordination of lawmaking on the federal and regional levels.
\end{abstract}

Keywords: Lawmaking, Democracy, Effectiveness, Law, Legislation, Reforms, Bill, Lawmaking process, Legal state, Lawmaking practice.

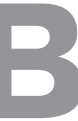

настоящее время демократические преобразования в нашей стране определяют курс на обновление и совершенствование действующего законодательства, изменения в котором происходят под непосредственным влиянием не только внутригосударственного, но и международного права. Через законотворчество во многом выражается демократическая природа государства и возможность формирования правового государства. Законодательство является инструментом демократизации всех сфер жизни общества, а результаты законотворческой работы говорят о степени демократичности государства. Важным является и то, что через законотворчество просматриваются формы и способы взаимосвязи государства, общества и личности.

Отметим, что главной идеей в период постперестроечного реформирования (положившего начало демократическим преобразованиям) явилась идея модернизации, когда законодательство стало необходимым инструментом демократизации всех сфер жизни общества, поскольку основной задачей было принятие новых законов с целью скорейшей замены нормативно-правовых актов, сопровождавших прежние экономический и социальный уклады. В условиях становления рыночных отношений и противоречивой российской действительности об эффективном правовом 
регулировании говорить не приходилось. Стихийное развитие законотворческой деятельности не являлось показателем обеспечения народовластия, демократизации законотворческой деятельности.

Профессор Ю.А. Тихомиров, рассуждая о происходящих процессах перестройки, верно указывал на важность обеспечения более органической связи демократизации, самоуправления с правом и законностью. По его мнению, если раньше трактовка демократии не связывала ее с законами о демократических институтах и процессах, то теперь право создает прочный юридический фундамент для развития активности граждан, для непосредственного принятия решений на основе общественного, народного волеизъявления ${ }^{1}$.

Эпоха «скороспелых» решений и радикальных преобразований прошла. Сегодня одной из тенденций развития законотворческого процесса является повышение авторитета закона, олицетворяющего собой принцип народовластия. Кроме того, становление демократической России совпало по времени с появлением в 1992 году Европейского Союза. Сегодня Россия как стратегический партнер не может находиться изолированно от Европы. В первую очередь это касается наднационального законотворчества, так как законодательная международная база требует переработки для адаптации и гармонизации с отечественным российским законодательством.

Современный механизм законотворчества Российской Федерации достаточно сложен и включает множество элементов. Законотворчество-процесс, состоящий из стадий законодательной инициативы, обсуждения законопроекта, принятия и опубликования закона. Эффективность законотворческого процесса зависит от ряда факторов, главным из которых является, на наш взгляд, совершенствование правовой базы законотворчества. Однако законотворчество сегодня не носит систематического характера. Большое количество принимаемых в нашей стране законов не говорит о стабильности законотворческого процесса.

Нельзя не согласиться с мнением профессора Н.И. Матузова о том, что закон может быть как атрибутом гражданского общества, так и фасадом тоталитарного государства, элементом демократии и инструментом власти, средством управления и механизмом принуждения, способом социальной регуляции и приемом ограничения прав и свобод личности. Он может выражать как идеалы добра, равенства,

\footnotetext{
${ }^{1}$ См.: Тихомиров Ю.А. Закон, стимулы, экономика. М.: Юрид.
} лит., 1989. С. 18 справедливости, так и служить проводником эгоистических интересов политиков. Закон может быть наполнен различным содержанием. Это одновременно и щит, и меч - в зависимости от обстоятельств ${ }^{2}$.

Цель настоящей статьи заключается в системном исследовании путей повышения эффективности законотворчества в современных условиях российских демократических преобразований.

В.Н. Казаков выделяет три фактора, влияющие на эффективность законотворчества.

Первая группа факторов носит объективный характер. России необходима реформа всей правовой системы и слепое заимствование чужих образцов бесполезно.

Вторая группа включает факторы, внешние по отношению к организации законодательного процесса, но создающие для него не благоприятные условия. Они вытекают из отсутствия опыта, культуры и традиций правового государства, в связи с обсуждением коллизий законодательства и указанного нормотворчества, из недостаточной активности Правительства как субъекта законодательной инициативы.

Третья группа касается организации и обеспечения законодательного процесса, в первую очередь законодательной процедуры. В этой группе факторов выделяются вопросы концептуального характера и организационные аспекты их реализации ${ }^{3}$.

К указанным выше факторам, оказывающим существенное влияние на законотворчество следует, на наш взгляд, добавить следующее: это большая роль политической конъюнктуры, принятие закона как результат компромисса между политическими элитами, что изначально снижает эффективность законотворческого процесса. Нередко принятие того или иного закона представляет собой давление на различные политические группы и лоббирование чьих-либо интересов.

В этой связи другой исследователь, Д.В. Казаков справедливо отмечает, что теория законотворчества ограничивается описанием и политически окрашенным обоснованием существующего законотворческого процесса в рамках конкретного общества и на определенном этапе его развития ${ }^{4}$.

\footnotetext{
${ }^{2}$ См.: Матузов Н.И. Диктатура закона как метод проведения правовой политики // Вестник Волжского университета им. В.Н. Татищева. Сер. «Юриспруденция». Вып. 12. Тольятти: ВУиТ, 2000. С.4, 6

${ }^{3}$ См.: Казаков В.Н. Факторы, влияющие на эффективность законотворчества //Государственная власть и местное самоуправление. 2013. № 12. СПС «КонсультантПлюс». Дата обращения -20.10 .2014 г

${ }^{4}$ См.: Казаков Д.В. Методологические проблемы исследования законотворчества //История государства и права. 2009. № 6. С. 5
} 


\section{Право и политика 5 (185) • 2015}

М.А. Мушинский предлагает отойти от сложившейся в науке концепции «факторов законотворчества», предлагая выделять не факторы правотворчества (законотворчества), а условия и факторы эффективности законодательства и условия и факторы эффективности правотворческой деятельности. В частности, к условиям эффективности правотворческой деятельности следует он относит:

- отлаженную систему правового мониторинга и прохождения правовой информации;

- профессионализм субъектов правотворческой деятельности;

- оптимальную систему экспертиз законопроектов (с точки зрения субъектного состава, научной, методической и организационной составляющей);

- активное, не формальное участие в правотворческой деятельности дополнительных субъектов, если это предусмотрено законодательством (к примеру, процедуры согласования проектов федеральных законов);

- реальное обеспечение в правотворческой деятельности населения и институтов гражданского общества (через процедуры народной правотворческой инициативы, публичных обсуждений проектов нормативных правовых актов, референдума);

- эффективное нормативно-правовое регулирование правотворческих процедур;

- четкое разграничение правотворческой компетенции между субъектами правотворчества;

- четкая организация правотворческой деятельности в правотворческих органах;

-необходимое финансовое и материально-техническое обеспечение ${ }^{5}$.

На сегодняшний день можно констатировать увеличение динамики законодательной деятельности, признать факт стабильного роста ежемесячно вносимых в Государственную Думу законопроектов. Кроме того, увеличивается количество законов о внесении изменений и дополнений в ранее принятые законы, а в особенности в кодифицированные акты, что свидетельствует о неустойчивости законотворческого процесса, избыточной нормативности. Так, например, 16 сентября 2014 года утверждена Примерная программа законопроектной работы Государственной Думы Федерального Собрания Российской Федерации в период осенней сессии 2014 года в части законопроектов, подлежащих первоочередному рассмотрению. Большая часть законопроектов касается изменений в кодексы, а

\footnotetext{
${ }^{5}$ См.: Мушинский М.А. Эффективность правотворческой деятельности и эффективность законодательства: соотношение и критерии //Юридическая техника. 2012. № 6. Нижний Новгород. С. 351-352
}

именно в Кодекс об административных правонарушениях, Уголовный кодекс, Уголовно-процессуальный кодекс, Гражданский кодекс, Земельный кодекс, Градостроительный кодекс, Кодекс внутреннего водного транспорта, Воздушный кодекс, Трудовой кодекс, Бюджетный кодекс, Налоговый кодекс ${ }^{6}$.

Приведем еще один пример в рамках рассматриваемой темы. 22.09.2014 г. депутатом Государственной Думы В.С. Селезневым Председателю Государственной Думы Федерального Собрания Российской Федерации был представлен в порядке законодательной инициативы проект федерального закона «О внесении изменений в отдельные законодательные акты Российской Федерации» с рекомендацией об изменении формулировок и дополнении положений в Гражданский, Градостроительный, Земельный кодексы 7

Между тем, усиление авторитета закона, его верховенство являются обязательным условием построения правового государства. Кодекс как систематизированный законодательный акт, содержащий нормы какойлибо отрасли права регулирует наиболее важные общественные отношения и должен отличаться от других нормативно-правовых актов тем, что регулирование с его помощью должно быть устойчивым, не подвергаться столь частым изменениям.

Сегодня различны по объему и значению многие законопроекты. Большую их часть было бы целесообразно вообще не предлагать на уровне законов, а урегулировать указами Президента РФ или правительственными постановлениями.

Во многом эффективность законотворческого процесса зависит от координации законотворческой деятельность Российской Федерации и ее субъектов. Региональное законотворчество не «отстает» от федерального по динамике, а иногда является более гибким, чем федеральное 8 .

\footnotetext{
${ }^{6}$ См.: Примерная программа законопроектной работы Государственной Думы Федерального Собрания Российской Федерации в период осенней сессии 2014 года в части законопроектов, подлежащих первоочередному рассмотрению (приложение к Постановлению Государственной Думы Федерального Собрания Российской Федерации рот 16 сентября 2014 года № 4845-6 ГД) // СПС «КонсультантПлюс». Дата обращения - 18.10.2014 г.

${ }^{7}$ Об этом см.: http://www.duma.gov.ru (Дата обращения 22.09.2014).

${ }^{8}$ Например, Саратовской областной Думой в 2013 году было рассмотрено 262 законопроекта (в 2012 - 243), из которых 242 (в 2012 году - 225) принято в двух чтениях, в том числе 77 базовых (в 2012 году - 54). См.: Доклад Саратовской областной Думы. Мониторинг законодательной деятельности Саратовской областной Думы в 2013 году. Саратов, 2014. С. 4
} 
Например, на уровне Российской Федерации обсуждается разработка и принятие законопроекта «Об основах государственной молодежной политики». Между тем, в отдельных регионах такие законы приняты уже давно: Закон Тюменской области «О молодежной политике в Тюменской области» от 06 февраля 1997 года за № 72 (в ред. от 24.04.2014 г. № 23), Закон Саратовской области от 9 октября 2006 г. № 94-3СО «О молодежной политике в Саратовской области» (в ред. от 01.08.2013 г. № 140-3СО) и др.

Отметим, что действенным механизмом последовательного совершенствования законодательства не только федеративного, но и субъектов Российской Федерации может стать институт народной правотворческой инициативы как институт непосредственной демократии.

Федеральный законодатель предусматривает реализацию права граждан на правотворческую инициативу. На основании ч. 1 ст. 6 Федерального закона от 6 октября 1999 г. № 184-Ф3 «Об общих принципах организации законодательных (представительных) и исполнительных органов государственной власти субъектов Российской Федерации» гражданам, проживающим на территории субъекта Российской Федерации, может быть предоставлено право законодательной инициативы в соответствии с Конституцией (уставом) субъекта Российской Федерации. Но федеральное законодательство не устанавливает формы реализации и правовые гарантии правотворческой инициативы граждан в правотворческих органах субъектов Российской Федерации. В этой связи верным является указание на то, что решение данная проблема находит в частичном восполнении данного пробела на уровне регионов, в нормативно-правовых актах которых определяется субъектный состав, предмет и содержание народной правотворческой инициативы, получают закрепление гарантии ее реализации, наиболее важные процедурные вопросы9.

Н.А. Власенко указывает на тенденции, сложившиеся в законотворческой практике: федеральный законотворческий процесс превратился в некое «латание дыр и прорех» - принимаются сотни поправок, дополнений и изменений, разработка самостоятельных законопроектов концептуального характера стала

\footnotetext{
${ }^{9}$ См.: Боровикова И.А., Гаврилова Л.В., Давыдова М.А., Шишпарёнок О.Н. Значение народной правотворческой инициативы на уровне субъектов Российской Федерации и ее место в непосредственной демократии //Вестник Института законодательства и правовой информации имени М.М. Сперанского. 2010. № 6(9). C. 6-7
}

редкостью; глубочайший кризис переживает региональное законотворчество; не разработаны критерии, с помощью которых можно определить, где грань или уровень федерального законотворчества и подзаконного нормотворчества ${ }^{10}$.

В.К. Самигуллин высказывает идею о том, что федеральный законодатель должен направлять правотворческую активность республиканского законодателя в единое правовое русло. Это требует более высокого уровня законотворческой деятельности федерального законодателя, активизации государственных структур, которые призваны укреплять федеративные начала, единство Российской Федерации и обеспечивать согласованное законотворчество, как по горизонтали, так и по вертикали ${ }^{11}$.

Отметим также, что внесение поправок и дополнений в законы сегодня распределяется неравномерно по наиболее важным сферам общественной жизни. Например, часто подвергаются изменениям налоговое законодательство, законодательство о социальном обеспечении, в то время как в другие законы (не менее важные) изменения и дополнения не вносятся.

На важную проблему разрушения старой нормативной системы и создание новой указал И.Ю. Козлихин. В процессе разрушения - созидания возможности закона как регулятора общественных отношений существенно ограничены. Коллизия закона становится обычным явлением, «свойством» изменяющегося права. Проявляется несоответствие между требованиями закона и состоянием правоприменительных и правозащитных органов, право не получает институциональной защиты. Часто обнаруживается несоответствие между содержанием закона и конкретной экономической, политической ситуацией, в то время как закон предназначен для регулирования повторяющихся, стандартных ситуаций ${ }^{12}$. Действительно, политико-правовая и социально-экономическая ситуация в стране претерпевает изменения на-

\footnotetext{
${ }^{10}$ Власенко Н.А. Кризис права: проблемы и подходы к решению // Журнал российского права. 2013. № 8. С. 48

${ }^{11}$ См.: Самигуллин В.К. Законодательная деятельность субъектов Федерации на пути ее совершенствования (на примере Республики Башкортостан) // Журнал российского права. 1998. № 4/5. С. 77-78. Здесь важным направление является искоренение противоречий между федеральным и региональным законодательством. Например, в ряде случаев нормы кодексов Республики Башкортостан противоречат общефедеральному законодательству (например, Кодекс Республики «О выборах» и т.д.).

${ }^{12}$ См.: Козлихин И.Ю. Право, закон и власть в современной России // Наш трудный путь к праву: Материалы философско-правовых чтений памяти академика В.С. Нерсесянца /Сост. В.Г. Графский. М.: Норма, 2006. С. 66-67
} 
DOI: $10.7256 / 1811-9018.2015 .5 .13535$

При цитировании этой статьи сноска на доі обязательна

\section{Право и политика 5 (185) 2015}

столько быстро, что зачастую законодательство является несвоевременным, устаревшим.

Можно констатировать, что вопросы повышения эффективности законотворческого процесса тесно связаны с темпоральностью норм, то есть их действии во времени. Как указывает Т.Л. Тенилова, категория «своевременность» является одним из средств воздействия на скорость осуществления правовых процессов. В правотворческом процессе она представляет собой минимальный отрезок времени от возникновения потребности в законе до его принятия. Данная категория является средством достижения истинности, эффективности, оптимальности, целесообразности, законности правовых норм, их соответствия нормам морали. Время - показатель и гарант демократичности, справедливости и гуманизма общества ${ }^{13}$.

Отмечая и признавая важность фактора своевременности принятия того или иного закона, можно на наш взгляд, привести пример об обсуждении законопроекта, касающегося масштабной реформы РАН. 27.09.2013 г. за № 253-Ф3 был принят Ф3 «О Российской академии наук, реорганизации государственных академий наук и внесении изменений в отдельные законодательные акты Российской Федерации». Между тем, законопроект вызвал неоднозначную оценку в научном сообществе и вызвал критику ученых и призыв отклонить данный законопроект, проводить реформирование в данной сфере только в связи со всесторонним обсуждением с научной общественностью, поскольку академическая наука усматривала в предлагаемом законопроекте лоббистские интересы чиновников.

Говоря об эффективности законотворческого процесса в условиях современных преобразований, следует сказать и о значимости научных центров, научно-консультативных советов, численность которых на настоящий момент явно недостаточна. Подготовка научных кадров - законотворцев, создание таких центров остается проблемой для юридической науки, при всей «массовости» современного юридического образования.

«...Среди депутатов Государственной Думы и членов Совета Федерации, равно как и законодательных органов субъектов Федерации, число юристов вообще и ученых-юристов в частности явно не соответствует потребностям перевода процесса формирования законотворческой политики и подготовки законопроектов на научную базу. Все это прямо сказывается на качестве принимаемых законов» (С.В. Поленина) $)^{14}$.

\footnotetext{
${ }^{13}$ См.: Тенилова Т.Л. Время в праве. Автореф. дис. ... канд. юрид. наук. Нижний Новгород, 1999. С. 6

${ }^{14}$ Поленина С.В. Законотворческая политика // Правовая политика России: теория и практика: монография / под ред. Н.И. Матузова и А.В. Малько. М.: ТК Велби, Изд-во Проспект, 2006. С. 220
}

Положительным моментом следует признать образование научно-консультативного совета обновленного объединенного нового Верховного Суда РФ. Так, было принято Положение о Научно-консультативном совете при Верховном Суде Российской Федерации, утвержденное Постановлением Пленума Верховного Суда РФ от 07.08.2014 № 8. Согласно п. 2 указанного Положения основной задачей Научно-консультативного совета является разработка научно обоснованных рекомендаций по принципиальным вопросам судебной практики, а также предложений по совершенствованию законодательства ${ }^{15}$.

Можно в полной мере согласиться с выводом, который делает Л.Б. Бутханова отмечая, что выделение первой стадии законодательного процесса - формирование научной основы выявления социальных проблем и задач, требующих законодательного разрешения, подготовка и обоснование вариантов законов и их возможных последствий, отбор предмета закона и определение порядка их разработки способствует более углубленному анализу социальных процессов и выработке научно обоснованных оценок полезности тех или иных вариантов законодательных актов, предотвращает формальный подход к принятию законов, гарантирует реальное и эффективное действие законодательных актов $^{16}$. Полагаем, что принципиально важный импульс развития вносит участие научной юридической среды в том плане, насколько обсуждаемые законопроекты будут выступать регулятором общественных отношений.

Одним из важных моментов в деле совершенствования законодательства является соответствие его критериям качества как в содержательном, так и в технико-юридическом смысле. Выделяют основные направления развития юридических технологий - юридическая техника; правовой мониторинг; научное проектирование развития законодательства на основе комплексных, системных исследований; целевой анализ системы законодательства, отдельных нормативных правовых актов, а также практики их применения и др. ${ }^{17}$

\footnotetext{
${ }^{15}$ См.: Положение о Научно-консультативном совете при Верховном Суде Российской Федерации (утверждено Постановлением Пленума Верховного Суда РФ от 07.08.2014 № 8) // СПС «КонсультантПлюс». Дата обращения - 20.10.2014 г.

${ }^{16}$ См.: Бутханова Л.Б. Процесс законотворчества в субъекте Российской Федерации: на примере Республики Бурятия. Автореф. дис. ... канд. юрид. наук. М., 1997. С. 16-17

${ }^{17}$ См.: Рашева Н.Ю. Понятие и сущность правового мониторинга как юридической технологии // Достижения вузовской науки. 2012.№ 2 . C.122
} 
В заключение отметим, что необходимость в увеличении роли законодательства объясняется его динамичным обновлением, ориентированием на личность, на признание, соблюдение и защиту прав и свобод человека и гражданина. Такая направленность объяс- няется демократическим развитием российского общества. Но достижение определенных положительных результатов в направлении повышения эффективности законотворчества предполагает разрешение основных законотворческих проблем.

\section{Библиография:}

1. Бутханова Л.Б. Процесс законотворчества в субъекте Российской Федерации: на примере Республики Бурятия. Автореф. дис. ... канд. юрид. наук. М., 1997. 25 с.

2. Боровикова И.А., Гаврилова Л.В., Давыдова М.А., Шишпарёнок О.Н. Значение народной правотворческой инициативы на уровне субъектов Российской Федерации и ее место в непосредственной демократии //Вестник Института законодательства и правовой информации имени М.М. Сперанского. 2010. № 6(9). С. 3-15

3. Доклад Саратовской областной Думы. Мониторинг законодательной деятельности Саратовской областной Думы в 2013 году. Саратов, $2014.156 \mathrm{c}$.

4. Казаков Д.В. Методологические проблемы исследования законотворчества //История государства и права. 2009. № 6. С. 5-7

5. Казаков В.Н. Факторы, влияющие на эффективность законотворчества //Государственная власть и местное самоуправление. 2013. № 12 //СПС «КонсультантПлюс»

6. Козлихин И.Ю. Право, закон и власть в современной России // Наш трудный путь к праву: Материалы философскоправовых чтений памяти академика В.С. Нерсесянца /Сост. В.Г. Графский. М.: Норма, 2006. С. 62-74

7. Матузов Н.И. Диктатура закона как метод проведения правовой политики // Вестник Волжского университета им. В.Н. Татищева. Сер. «Юриспруденция». Вып. 12. Тольятти: ВУиТ, 2000. С. 3-12

8. Мушинский М.А. Эффективность правотворческой деятельности и эффективность законодательства: соотношение и критерии //Юридическая техника. 2012. № 6. Нижний Новгород. С. 347-352

9. Поленина С.В. Законотворческая политика // Правовая политика России: теория и практика: монография / под ред. Н.И. Матузова и А.В. Малько. М.: ТК Велби, Изд-во Проспект, 2006. С. 219-247

10. Самигуллин В.К. Законодательная деятельность субъектов Федерации на пути ее совершенствования (на примере Республики Башкортостан) // Журнал российского права. 1998. № 4/5. С. 70-79

11. Тенилова Т.Л. Время в праве. Автореф. дис. ... канд. юрид. наук. Нижний Новгород, 1999. 32 с.

12. Тихомиров Ю.А. Закон, стимулы, экономика. М.: Юрид. лит., 1989. 272 с.

13. Рашева Н.Ю. Понятие и сущность правового мониторинга как юридической технологии // Достижения вузовской науки. 2012.№ 2 .C. $130-137$

\section{References (transliterated):}

1. Butkhanova L.B. Protsess zakonotvorchestva v sub"ekte Rossiiskoi Federatsii: na primere Respubliki Buryatiya. Avtoref. dis. ... kand. yurid. nauk. M., 1997. 25 s.

2. Borovikova I.A., Gavrilova L.V., Davydova M.A., Shishparenok O.N. Znachenie narodnoi pravotvorcheskoi initsiativy na urovne sub'ektov Rossiiskoi Federatsii i ee mesto v neposredstvennoi demokratii //Vestnik Instituta zakonodatel'stva i pravovoi informatsii imeni M.M. Speranskogo. 2010. № 6(9). S. 3-15

3. Kazakov D.V. Metodologicheskie problemy issledovaniya zakonotvorchestva //Istoriya gosudarstva i prava. 2009. № 6. S. 5-7

4. Kazakov V.N. Faktory, vliyayushchie na effektivnost' zakonotvorchestva //Gosudarstvennaya vlast' i mestnoe samoupravlenie. 2013. № 12 //SPS «Konsul’tantPlyus»

5. Kozlikhin I.Yu. Pravo, zakon i vlast' v sovremennoi Rossii // Nash trudnyi put' k pravu: Materialy filosofsko-pravovykh chtenii pamyati akademika V.S. Nersesyantsa /Sost. V.G. Grafskii. M.: Norma, 2006. S. 62-74

6. Matuzov N.I. Diktatura zakona kak metod provedeniya pravovoi politiki // Vestnik Volzhskogo universiteta im. V.N. Tatishcheva. Ser. «Yurisprudentsiya». Vyp. 12. Tol'yatti: VUiT, 2000. S. 3-12

7. Mushinskii M.A. Effektivnost' pravotvorcheskoi deyatel'nosti i effektivnost' zakonodatel'stva: sootnoshenie i kriterii // Yuridicheskaya tekhnika. 2012. № 6. Nizhnii Novgorod. S. 347-352

8. Polenina S.V. Zakonotvorcheskaya politika // Pravovaya politika Rossii: teoriya i praktika: monografiya / pod red. N.I. Matuzova i A.V. Mal'ko. M.: TK Velbi, Izd-vo Prospekt, 2006. S. 219-247

9. Samigullin V.K. Zakonodatel'naya deyatel'nost' sub"'ektov Federatsii na puti ee sovershenstvovaniya (na primere Respubliki Bashkortostan) // Zhurnal rossiiskogo prava. 1998. № 4/5. S. 70-79

10. Tenilova T.L. Vremya v prave. Avtoref. dis. ... kand. yurid. nauk. Nizhnii Novgorod, 1999. 32 s.

11. Tikhomirov Yu.A. Zakon, stimuly, ekonomika. M.: Yurid. lit., 1989. 272 s.

12. Rasheva N.Yu. Ponyatie i sushchnost' pravovogo monitoringa kak yuridicheskoi tekhnologii // Dostizheniya vuzovskoi nauki. 2012.№ 2 .S. 130-137 